\title{
CONGENITAL DEAFNESS AND HAEMOLYTIC DISEASE OF THE NEWBORN
}

BY

\author{
L. FISCH and D. A. OSBORN
}

From the Audiology Unit of the Royal National Throat, Nose and Ear Hospital, London, and the Department of Pathology in the Institute of Laryngology and Otology, London

(RECEIVED FOR PUBLICATION FEBRUARY 22, 1954)

The association of deafness with haemolytic disease of the newborn has been reported by several authors in the past few years. Goodhill (1950) attempted a follow-up of 46 cases of haemolytic disease of the newborn. Of the 15 cases he managed to trace, two showed a significant degree of perceptive deafness. In a further investigation he obtained birth histories from the mothers of 904 severely deaf children, and amongst these he found 27 probable, four possible and nine doubtful cases of isoimmunization. Crabtree and Gerrard (1950) recorded 16 cases of perceptive deafness associated with kernikterus. Gerrard (1952) carried out a retrospective inquiry on 407 deaf school children. Information was obtainable from the parents of $\mathbf{3 6 0}$ and of these 33 were jaundiced in early infancy, five of them showing evidence of iso-immunization involving the $R h$ system with mild neurological signs. Johnsen and Freiesleben (1952), during routine examination of school children, found 50 cases of high-frequency deafness in which other known causes did not appear to be operative. In 10 of these there was $\mathrm{Rh}$ incompatibility between mother and child, and maternal antibodies were demonstrated in five. Evans and Polani (1950) examined 16 cases in which there were neurological sequelae to $\mathrm{Rh}$ iso-immunization. Of these, five $(30 \%)$ were deaf.

The object of the present paper is to record the results of a retrospective inquiry on a large number of deaf patients with a view to ascertaining what proportion might be associated with iso-immunization in the mothers of these cases during pregnancy. The pattern of deafness has also been studied in such cases and compared with cases of perceptive deafness due to other causes.

\section{Material and Methods}

Between January, 1951, and September, 1953, 1,806 deaf children attended the Audiology Unit of this hospital. Of these 891 had congenital perceptive deafness and the primary task was to select from this total cases in which haemolytic disease had been present at birth.

The criteria for the establishment of such a diagnosis fall into three groups-clinical, haematological and serological. The clinical triad, jaundice, anaemia and neurological signs, provides very strong evidence in favour of the diagnosis, but confirmation depends upon the serological evidence-blood group incompatibility between mother and child, the presence of maternal antibodies and, above all, a positive direct anti-human globulin test on the child's red cells at birth. The haematological evidence, low cord-blood haemoglobin, excessive numbers of nucleated red cells and a high serum bilirubin, is useful in confirmation.

A primary selection was made on the basis of the clinical criteria, it being assumed that at least one of these must have been observed in all cases. Admittedly, sub-clinical cases may well have been missed in this way, but the chances of detecting such cases on other evidence were so small that there was little to be gained by adopting any other procedure. The result of this preliminary selection was a much smaller group of cases which were then subjected to closer study and investigation along the following lines.

Clinical. Detailed histories, including maternal obstetric data were obtained. Physical examinations were made with particular reference to the nervous system and ear function.

Serological. The blood groups of mother and patient were checked (ABO and Rh) and tests for the presence of maternal antibodies were performed, where possible using the patient's own cells. In quite a few cases detailed investigations had been carried out at the time of birth and a considerable amount of information was obtained from the hospitals concerned. In many cases the blood groups were not known and had to be determined. Rh grouping was 

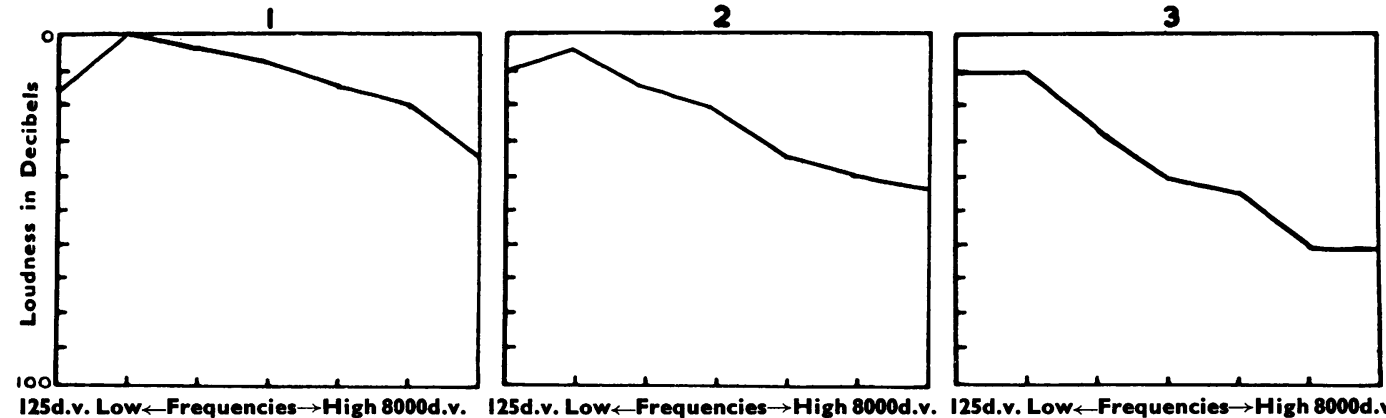

125d.v. Low $\leftarrow$ Frequencies $\rightarrow$ High 8000d.v. 125d.v. Low $\leftarrow$ Frequencies $\rightarrow$ High 8000d.v.

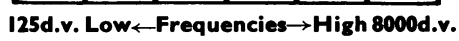

5

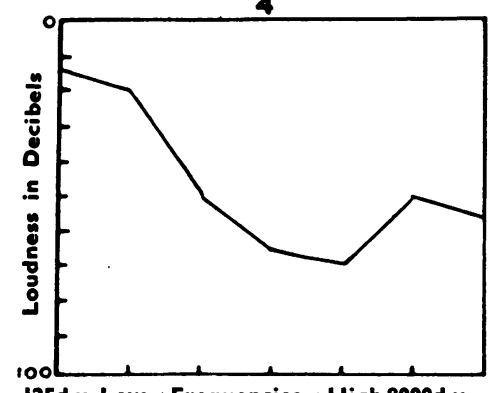

125d.v. Low $\rightarrow$ Frequencies $\rightarrow$ High 8000d.v. I25d.v. Low $\rightarrow$ Frequencies $\rightarrow$ High 8000d.v. I25d.v. Low $\rightarrow$ Frequencies $\rightarrow$ High 8000d.v.

Figs. 1-6.-Audiograms showing slight or moderate degree of deafness. These patients had no apparent neurological complications.

confined solely to the use of anti-D. In a few cases the current determination of antibodies was of help but in others the result had to be interpreted in the light of the lapse of time and the occurrence of subsequent pregnancies. Some of the patients were born before the relevant serological investigations were in common use, and this applied particularly to the anti-human globulin test (Coombs, Mourant and Race, 1945).

For a variety of reasons beyond our control it was not always possible to obtain all the relevant information, but careful scrutiny of the available clinical and laboratory data in each individual case enabled an assessment to be made in the majority. The cases were divided into categories according to whether there was or was not confirmatory evidence of haemolytic disease of the newborn. Where such evidence existed, the cases were classified further as certain (I) or probable (II). The unconfirmed group included cases in which the diagnosis was possible (III), cases which were judged on the serological evidence not to have had haemolytic disease (IV), and finally those cases in which there was insufficient information to draw any conclusion (V). Ideally, the diagnosis would be certain if the following features were present: (i) Clinical signs, (ii) blood group incompatibility, (iii) maternal antibodies present at birth and (iv) a positive direct antihuman globulin test on the child's cells at birth.

The last was rarely present for the reason given above and its absence was not considered a bar to inclusion of the case in category $I$. Wherever doubt existed, the case was always relegated to a lower category, hence any error is by way of being an under-estimate of the total number of cases.

\section{Results}

From a total of 891 cases of congenital perceptive deafness, 69 were selected on the basis of the clinical criteria for further investigation. As a result of their final assessment they were placed in categories as indicated in Table 1.

TABLE 1

ANALYSIS OF 69 CASES WITH CLINICAL FEATURES OF HAEMOLYTIC DISEASE OF THE NEWBORN

\begin{tabular}{c|c|c|c|c|c}
\hline Category & I & II & III & IV & V \\
\hline Diagnosis & Certain & Probable & Possible & No supporting evidence & Inadequate information \\
\hline No. of cases.. &.$\cdot$ & 18 & 9 & 19 & 16 \\
Percentage of total (891) .. & 2 & 1 & & \\
\hline
\end{tabular}


TABLE 2

RELEVANT SEROLOGICAL FINDINGS IN 27 CERTAIN OR PROBABLE CASES OF HAEMOLYTIC DISEASE OF THE NEWBORN

\begin{tabular}{|c|c|c|c|c|c|c|c|}
\hline \multirow{2}{*}{ Case No. } & \multirow{2}{*}{ Category } & \multirow{2}{*}{$\begin{array}{c}\text { Direct } \\
\text { Anti globulin } \\
\text { Test }\end{array}$} & \multicolumn{2}{|c|}{ Blood Groups } & \multirow{2}{*}{$\begin{array}{l}\text { Maternal } \\
\text { Antibodies }\end{array}$} & \multirow{2}{*}{$\begin{array}{l}\text { Subsequent } \\
\text { Pregnancy }\end{array}$} & \multirow{2}{*}{$\begin{array}{c}\text { Time Lapse } \\
\text { Last Pregnancy } \\
\text { to Test }\end{array}$} \\
\hline & & & Patient & Mother & & & \\
\hline $\begin{array}{l}1 \\
2 \\
3 \\
4 \\
5 \\
6 \\
7 \\
8 \\
99 \\
10 \\
11 \\
12 \\
13 \\
14 \\
15 \\
16 \\
17 \\
18 \\
19 \\
20 \\
21 \\
22 \\
23 \\
24 \\
25 \\
26 \\
27\end{array}$ & $\begin{array}{l}\text { I } \\
\text { II } \\
\text { II } \\
\text { II } \\
\text { II } \\
\text { I } \\
\text { II } \\
\text { II } \\
\text { I } \\
\text { II } \\
\text { II } \\
\text { II } \\
\text { II } \\
\text { II } \\
\text { I } \\
\text { I } \\
\text { II } \\
\text { II } \\
\text { I } \\
\text { I } \\
\text { I } \\
\text { I } \\
\text { I }\end{array}$ & $\begin{array}{l}+ \\
+ \\
+ \\
+ \\
+ \\
+ \\
+\end{array}$ & 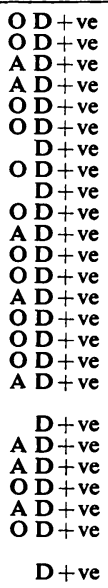 & 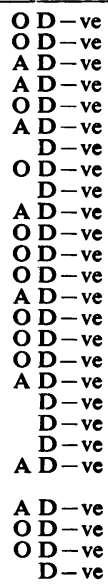 & $\begin{array}{l}+ \\
+ \\
+ \\
\pm \\
+ \\
+ \\
\pm \\
\pm \\
+ \\
\pm \\
+ \\
+ \\
+ \\
+ \\
+ \\
+ \\
+ \\
+ \\
+ \\
+ \\
+ \\
+ \\
+ \\
+\end{array}$ & $\begin{array}{l}1 \\
\frac{1}{-} \\
1 \\
\frac{1}{2} \\
= \\
= \\
\frac{2}{2} \\
\overline{1} \\
\frac{1}{-} \\
= \\
= \\
= \\
- \\
=\end{array}$ & $\begin{array}{l}\text { At birth* } \\
6 \text { yr. } \\
\text { At birth } \\
16 \text { yr. } \\
6 \text { yr. } \\
\text { At birth } \\
\text { At birth } \\
15 \mathrm{yr} . \\
9 \mathrm{yr} . \\
55 \text { yr. } \\
\text { At birth } \\
13 \text { yr. } \\
\text { At birth } \\
\text { At birth } \\
\text { At birth } \\
19 \text { yr. } \\
\text { At birth } \\
\text { At birth } \\
\text { At birth } \\
\text { At birth } \\
\text { At birth } \\
\text { At birth } \\
\text { At birth } \\
5 \frac{1}{2} \text { yr. }\end{array}$ \\
\hline
\end{tabular}

* At birth of patient.

It will be seen that in 27 cases there were strong grounds for believing that haemolytic disease of the newborn had been present at birth, and in two-thirds of these the diagnosis was beyond all reasonable doubt. The incidence of haemolytic disease in congenital perceptive deafness is 3 or $2 \%$, according to whether or not the patients in the second category are accepted as bona fide cases of haemolytic disease. The relevant details of the cases in these first two categories are given in Table 2.

The average age of the patients was between 8 and 9 years. Only one was a first child, the mother having previously received a transfusion for a miscarriage. In all these cases iso-immunization involved the Rh system. In no case was involvement of any other blood group system encountered although in three cases with jaundice at birth (two having neurological signs), $\mathrm{ABO}$ incompatibility between mother and child was present. However, in view of the greater difficulty in confirming such cases, especially in retrospect, these three were relegated to category III (possible).

Clinical Examination of Cases in Categories I and II. All cases had a history of jaundice in early infancy, and 10 were known to be anaemic at birth, six others receiving transfusions. Twenty patients had various degrees of cerebral palsy, and seven were free from apparent neurological signs (other than deafness). Otological examination revealed no evidence of middle-ear disease. Vestibular response was investigated in 17 using Bárány's turning test. Post-rotatory nystagmus was observed in all patients, being assessed as normal in 11 and diminished in five. In one child a coarse nystagmus with severe vertigo was elicited. An investigation of vestibular function by caloric stimulation was not undertaken in this particular series.

The mental condition could be assessed with reasonable accuracy in 16, of whom 14 were normal, one mentally defective and one backward. In the remaining 11 children no final assessment could be made but there was no cause to believe that they were mentally retarded, since they all responded well to various measures of educational treatment. All children started to talk late and had varying degrees of speech defect. The seven children without neurological complications had otherwise normal milestones. Fifteen were late sitting up and walking and five sat up at 6 months but started to walk late.

The speech defect in those without motor disturbances was typical of that found in children with perceptive deafness, and was characterized by omission of high frequency sounds resulting in defective consonants. In the remainder, the speech defect was the result of both deafness and neuromuscular incoordination. Speech required an obvious physical effort and was fragmentary, high frequency sounds being omitted. There was con- 
7

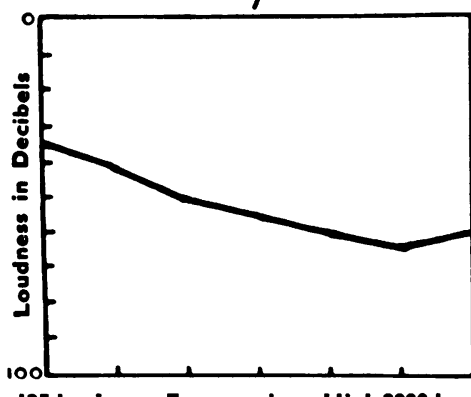

I25d.v. Low $\leftarrow$ Frequencies $\rightarrow$ High 8000d.v.

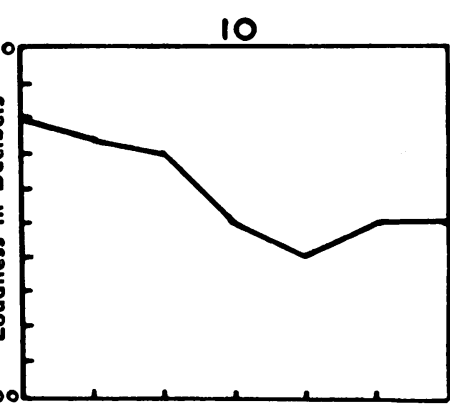

I25d.v. Low $\leftarrow$ Frequencies $\rightarrow$ High 8000 d.v.
Figs. 7-10.-Audiograms showing a moderate degree of deafness, on the whole severer than in Figs. 1-6. These patients had moderate degrees of neurological complication.

tinued inaccurate imitation of the speech sounds and articulate language was at a lower level than the connected thought because of the effort required. Retarded language development resulted not only from the high frequency deafness but also from the inevitable difficulties of learning (e.g., rhythmical and frequent repetition). Intonation had a smaller range than one would expect in a cerebral palsied child with normal hearing.

Hearing. Perceptive deafness of varying degree was diagnosed in all 27 cases. The age at which deafness was suspected ranged from 6 months to 11 years, the average being $3 \frac{1}{2}$ years. The time lapse between deafness being suspected and attendance at the clinic varied from 6 months to 10 years.

It is difficult to present the hearing loss of a large number of individuals when they are considered as a single group. Some idea can be obtained from the type of education recommended, this being based on the evaluation of the patient as a whole (capacity to hear speech, intelligence, personality, etc.). Analysis of two extreme groups, those attending a normal school (seven cases), and those in a school for the deaf (seven cases), already indicated a certain pattern of deafness. Children attending normal schools had a slight or moderate degree of deafness. None of them had a total or very severe
8
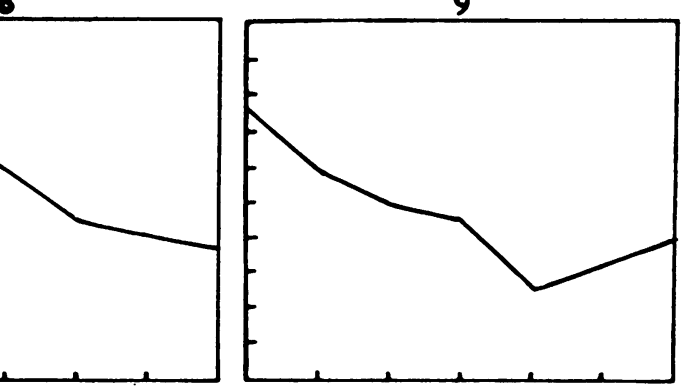

125d.v. Low $\leftarrow$ Frequencies $\rightarrow$ High 8000d.v.

loss of hearing for high frequencies; they could hear vowels very well, and consonants well enough to correct their speech defect. The majority of the deaf-school group had very severe or total loss of hearing for high frequencies. Vowel discrimination was good, but they were unable to hear consonants and communication by speech was only possible with the help of lip-reading. If speech training had not been started early enough it was difficult to correct defects (lack of auditory discrimination, Whetnall, 1952).

This pattern of deafness became clearer when the audiograms were grouped together according to apparent similarities.

In 18 out of the 27 it was possible to obtain a reliable audiogram. Six patients were too young and in three the result was not considered reliable. Hearing tests in children with cerebral palsy are difficult to perform because their physical reaction to sound stimuli may be delayed or altered. The child should be conditioned to the sound stimulus to perform some simple manual operation, which must be sufficiently complicated to leave no doubt that it is deliberate, and yet simple enough for the handicapped child to perform. A good method is to get the child to remove objects from a box on hearing the sound. In this way, with care and patience, results can be obtained comparable with those in the otherwise physically normal children.

In each patient only the audiogram of the better ear is presented. The results fall into two main groups: in the first (audiograms Nos. 1-10) there is moderate or severe loss of hearing for high frequencies, and in the second (audiograms Nos. 11-17) there is a subtotal or total loss for high frequencies. There is little difference in the hearing loss for lower frequencies between the two groups. One audiogram is not included in this analysis because the test was carried out by a different method, the psychogalvanic test (Bordley and Hardy, 1949), which does not depend upon the subjective cooperation of the 
11

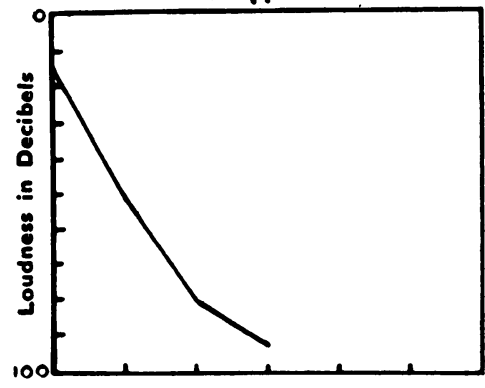

125d.v. Low $\leftarrow$ Frequencies $\rightarrow$ Highjo000d.v.

14

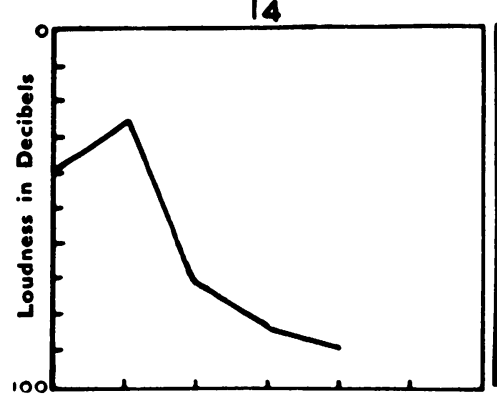

125d.v. Low $\leftarrow$ Frequencies $\rightarrow$ High 8000d.v. I25d.v. Low $\leftarrow$ Frequencies $\rightarrow$ High 8000d.v.

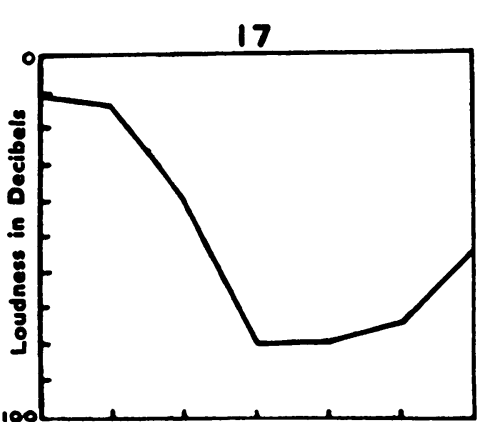

I25d.v. Low $\rightarrow$ Frequencies $\rightarrow$ High 8000 d.v.

12

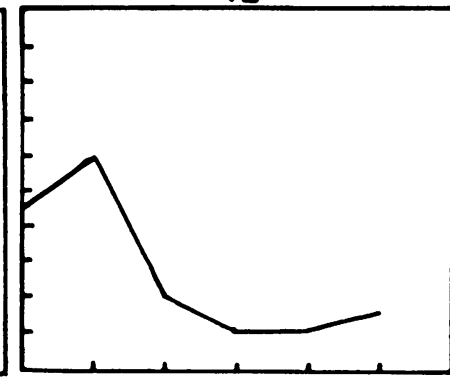

15

Figs. 11-17.Audiogram s showing total or very severe loss of hearing for high frequencies. All these patients also had sever e neurological complications. 125d.v. Low $\leftarrow$ Frequencies $\rightarrow$ High 8000 d.v. I25d.v. Low $\leftarrow$ Frequencies $\rightarrow$ High 8000 d.v.

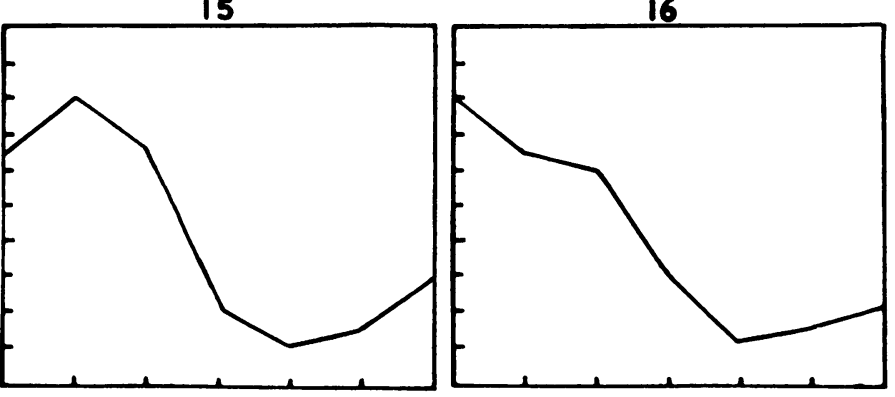

patient. The audiogram is reproduced here and it is interesting to note that it is almost identical with those in the second group (audiogram 18).

In so far as the deafness and the other neurological signs may have a common pathogenesis, any correlation between their respective degrees of severity is obviously relevant. Examination of the audiograms from the patients with and without other neurological signs showed that the group with the total or very severe high-frequency loss also had severe neurological complications. Of the 10 graphs showing the less severe high-frequency loss, four belonged to patients exhibiting moderate degrees of motor disturbance, and their deafness was somewhat more severe than that of the remain- 125d.v. Low $\leftarrow$ Frequencies $\rightarrow$ High 8000 d.v.
Fig. 18.-Pattern of audiogram in deafness using the psychogalvanic test.

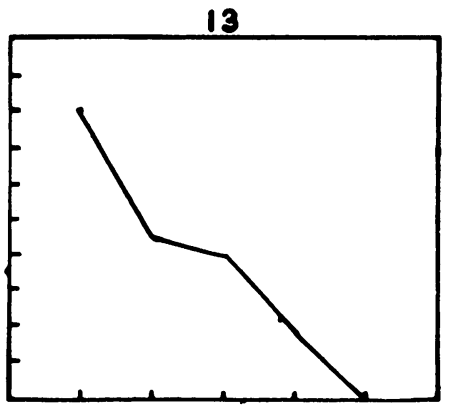

16

ing six in this group who were free from neurological complications. An assessment of the nine patients in whom audiograms were not obtained showed that three had severe deafness and severe neurological complications, five had moderate deafness of whom two had severe and three had moderate neurological complications, and one had moderate deafness with no other neurological signs. The following is the composite picture:

Neurological complications absent

Neurological complications present 
This analysis suggests that a direct correlation between severity of deafness and of other neurological signs may exist.

In the comparison with other types of congenital perceptive deafness 297 cases were studied. It is important to note that the comparison was not purely one of audiograms but also of many other features. Deafness in these patients was not considered as an isolated symptom, but was studied in relation to the individual as a whole. The various groups are summarized in the following paragraphs, and the audiograms referred to are composite ones representative of each group.

Maternal Rubella Deafness (69 Cases). General health was often below standard and there was a marked tendency to upper respiratory infections. Occasional heart and eye lesions were encountered. Excitability was often a feature, and in the majority some form of behavioural disorder was common. Intelligence was normal in the majority.

The audiogram was of horizontal type (No. 19) and there was usually moderate or moderately severe deafness, but good discrimination of all speech sounds. Hypersensitivity to loud sounds was frequently reported. Vestibular response was present though occasionally diminished. A hearing aid is useful.

Heredity (50 CASES). Two distinct types are recognizable.

19 MATERNAL RUBELla

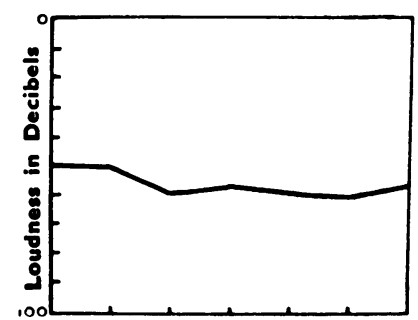

125d.v. Low $\leftarrow$ Frequencies $\rightarrow$ High 8000 d.v.

22 ANOXIA, PREMATURITY AND BIRTH INJURY

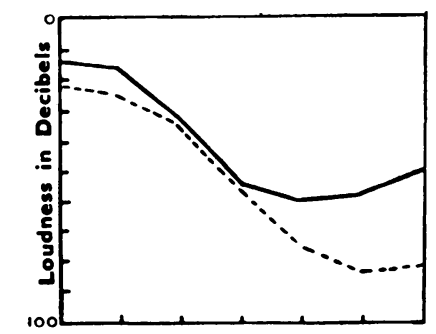

25d.v. Low $\leftarrow$ Frequencies $\rightarrow$ High 8000 d.v.
Type I. General health was usually good, the children were emotionally well adjusted, and mental ability was within normal limits. Vestibular response was usually absent.

Residual hearing was present in the lower frequencies only (No. 20), but vowel discrimination was present in some. A hearing aid is of limited use, but it supplies useful auditory experience and helps in education.

Type II. General health, emotional adjustment and mental ability were within normal limits. Vestibular response was usually present.

There was moderate or moderately severe hearing loss greater in the higher frequencies giving a gently sloping audiogram (No. 21). Vowel discrimination was good and there was fair hearing for consonants. A hearing aid is useful.

ANoxia AND BirTh INJURy (83 CASES) AND Prematurity (68 Cases). Analysis of these groups showed no significant difference. Reliable audiograms were obtained in $\mathbf{1 8}$ of the anoxia group and in 24 of the prematurity group, and although they have not been subjected to statistical analysis, the vast majority formed a pattern of predominantly high frequency loss. In some the loss was very severe and in others rather less so, but none showed more than moderate low frequency loss (No. 22). Vestibular response was normal in all these cases. In the premature group, the general health was often below standard and there was a large
Figs. 19-23. - Pattern of audiograms in deafness associated with selected pathological conditions.

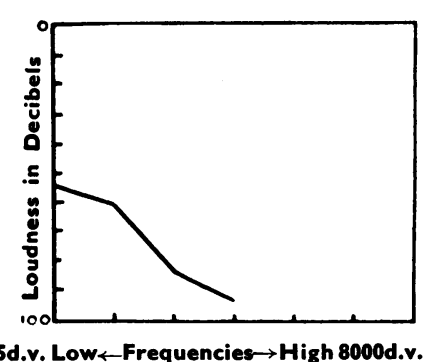

125d.v. Low $\leftarrow$ Frequencies $\rightarrow$ High 8000d.v.

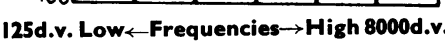

23 ERYTHROBLASTOSIS

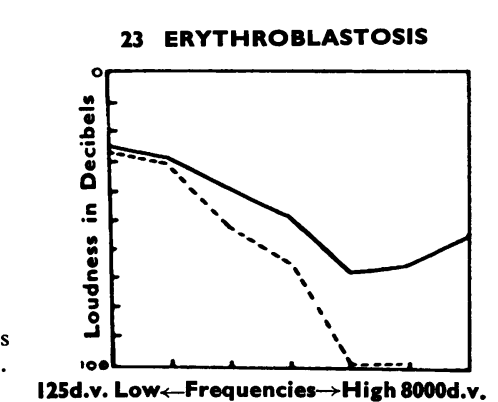

125d.v. LoW $\leftarrow$ Frequencies $\rightarrow$ High 8000d.v.

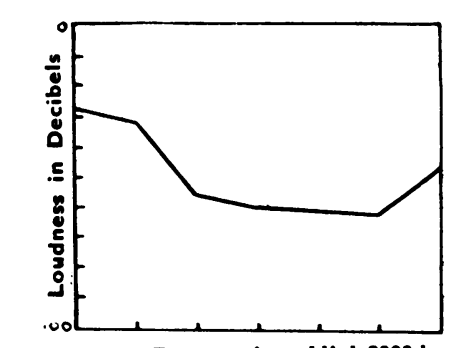

125d.v. Low $\leftarrow$ Frequencies $\rightarrow$ High 8000 d.v. 
number of children who were not emotionally well adjusted.

Haemolytic Disease of the Newborn (27 CASES). Most showed various degrees of cerebral palsy (choreo-athetosis). In the majority the intelligence was normal and they were emotionally well adjusted.

Audiograms showed either moderate or severe high frequency loss (No. 23). Hypersensitivity to loud sounds was not reported. Vestibular response was present. A hearing aid is useful in the moderate but less so in the severe type.

\section{Discussion}

The incidence of haemolytic disease of the newborn in the general population is not known with any degree of certainty, but it is usually estimated at 1 in 200 of all pregnancies (Mollison et al., 1952). This does not really give a figure for comparison because it takes no account, in particular, of the survival rate of cases of haemolytic disease. The mortality from this condition is still high and must have been higher at the time of birth of many of the children now under review. Hence it is reasonable to assume that the incidence amongst surviving children in this particular period was certainly not more than $0.5 \%$ and was probably considerably less. Even if this figure were correct, the observed incidence in deaf children ( 2 and probably $3 \%$ ) is highly significant $(\mathrm{P}<1: 1000)$.

The detection of deafness in these children, especially in those with cerebral palsy, is not easy. Defective speech is a good pointer to hearing defect in the otherwise physically normal, but in those with paralysis of cerebral origin it may be merely a manifestation of disturbance of motor function. There are, however, a few helpful signs to look for in these cases. If some speech has developed, high frequency sounds may be omitted and there is a continued inaccurate imitation of the speech sounds with a defect in pronouncing consonants, especially sibilants. The child will lip read and intonation may have a smaller range than would be expected in a child with cerebral palsy but normal hearing. After a period of observation and training, the presence of an additional cause for speech defect will gradually become apparent to an experienced teacher.

Auditory function involves much more than the hearing of pure tones registered by an audiogram which, therefore, does not give the complete picture. However, an audiogram does present a definite picture of a disturbance of function in the auditory pathway. A lesion in a particular site will result in loss of hearing which is consistently associated with a certain type of audiogram, and a pattern can actually be detected in deafness associated with selected pathological conditions. This fact is brought out in the comparative study of various types of congenital deafness. Predominant high frequency loss is a common finding in cases of perceptive deafness irrespective of the cause, but it was thought that the particular patterns of deafness associated with anoxia, birth injury and prematurity on the one hand and haemolytic disease on the other, showed similar features suggesting the possibility of a common site of lesion. However, further study is necessary to verify the true identity of these patterns.

Gerrard (1952) examined two cases of kernikterus after death and found the cochlea normal but the cochlear nuclei showed degeneration of the nerve cells. Nuclear staining and degeneration and subsequent disappearance of the nerve cells have been described by many workers since the first case of kernikterus was recorded by Orth (1875). The vast majority of cases have come to necropsy soon after birth. Examinations at a later date have been relatively few and particular reference to the cochlear nuclei has rarely been made.

For obvious reasons, the condition of the cochlear nuclei in cases which have suffered from perceptive deafness is not accurately known, but in those cases where deafness is associated with the neurological manifestations of kernikterus, it is reasonable to assume that the lesions are of a similar nature and origin. The pathogenesis of damage to the cochlear nuclei and hence, presumably, the cause of perceptive deafness in cases of haemolytic disease of the newborn is, therefore, that of kernikterus in general.

A wide variety of theories have been advanced in recent years to explain this condition. Furthermore, many cases have now been described in which there is no serological evidence of iso-immunization, and there is a growing belief that kernikterus is not, as was thought formerly, pathognomonic of haemolytic disease. Of the various suggested aetiological factors, two are of particular interest in the present connection. Claireaux (1950) suggested that the nuclear masses were susceptible to anoxia consequent upon the severe anaemia associated with haemolytic disease, and Govan and Scott (1953) carried this concept a stage further when they reported 10 cases of kernikterus without evidence of haemolytic disease but with a history of asphyxia at birth. Aidin, Corner and Tovey (1950) recorded 25 cases of kernikterus at necropsy with no evidence of haemolytic disease, and 24 of their cases were premature. These authors suggested that prematurity played an important part in the pathogenesis of the condition. 
In the present series the possible effects of isoimmunization only have been considered. In none of the 27 cases was there any obstetric history suggesting the occurrence of asphyxia, and in seven only could a history of prematurity be elicited. There was no evidence of any relationship between prematurity and the degree of deafness. Whatever part anoxia may have played in the pathogenesis of deafness in these cases, prematurity can hardly be regarded as having had any material influence. However, comparison with cases of perceptive deafness not associated with haemolytic disease is interesting, particularly from the point of view of the audiograms. As already mentioned, the pattern of hearing loss was thought to be similar in both haemolytic disease and in that group of cases in which anoxia was present for other reasons. In maternal rubella and the hereditary types of deafness there is interference with cochlear development while in the anoxic and haemolytic disease groups cochlear development is normal. It is tentatively suggested that congenital perceptive deafness may be of two types, cochlear or nuclear, according to the site of the lesion. The linking together in this way of the two types of deafness associated with haemolytic disease and anoxia respectively may indicate a common site of the lesion but not necessarily a common aetiology, although the association of kernikterus with asphyxia in Govan's cases would suggest a closer causal relationship.

The predominance of high-frequency loss of hearing in these cases requires further comment. In theory, high-frequency loss could be explained in terms of selective lesions anywhere in the auditory pathway. There is no evidence that the organ of Corti is damaged in these cases nor, it must be admitted, any certain proof to the contrary, though if it were, an explanation of the selective damage to the basal portion would still be necessary. The dorsal cochlear nucleus, as distinct from the ventral, is the one place where the high frequency fibres are probably completely separated from the low (Lewy and Kobrak, 1936). The bilateral nature of the condition indicates some peculiarity in the highfrequency pathway which renders it more susceptible to damage. The problem of the selective vulnerability of the auditory pathway is clearly one for much further study.

The result of this investigation leaves little doubt that iso-immunization plays a part in the pathogenesis of congenital perceptive deafness which seems to be linked with the condition of kernikterus. A considerable proportion of cases still remain without a known aetiological basis, and the fact that kernikterus may arise in other circumstances suggests that perhaps a new light may be thrown on yet a few more of these cases of congenital deafness.

The correct diagnosis of the cause of congenital deafness is of more than academic interest. Not only does it help to reduce the number of unclassified cases, but by establishing associated conditions, it promotes early detection and facilitates necessary speech training. To this end, although iso-immunization accounts for only a small number of the total, it is recommended that children who survive haemolytic disease of the newborn should have their hearing tested at a clinic where full facilities exist for this type of work.

\section{Summary}

In an investigation of 891 children with congenital perceptive deafness, evidence of haemolytic disease of the newborn was found in 27, of whom 20 had varying degrees of choreo-athetosis. There appeared to be some correlation between the degree of deafness and the severity of other neurological signs.

These cases were compared with other cases of congenital perceptive deafness associated with anoxia and birth injury (83), prematurity (68), heredity (50) and maternal rubella (69). A similarity was noted between the audiograms of the cases associated with haemolytic disease and anoxia respectively in both of which there is selective high-frequency loss. It is suggested that in these two groups there is at least a common site of the lesion if not a common aetiology.

We gratefully acknowledge all the hospitals which so kindly supplied results of serological investigations carried out at the births of a proportion of our patients. Our thanks are due to Miss E. Whetnall, Director of the Audiology Unit, and to Dr. I. Friedmann, Director of the Department of Pathology, for advice and encouragement, and also to the various members of the staffs of the Audiology Unit, the Pathology Laboratory, and the Department of Clinical Photography for their assistance.

\section{BIBLIOGRAPHY}

Aidin, R., Corner, B. and Tovey, G. (1950). Lancet, 1, 1153.

Bordley, J. E. and Hardy, W. G. (1949). Ann. Otol., St. Louis, 58,751 .

Claireaux, A. (1950). Archives of Disease in Childhood, 25, 61.

Coombs, R. R. A., Mourant, A. E. and Race, R. R. (1945). Lancet, $2,15$.

Crabtree, N. and Gerrard, J. (1950). J. Laryng., 64, 482.

Evans, P. R. and Polani, P. E. (1950). Quart. J. Med., new series, $19,129$.

Gerrard, J. (1952). J. Laryng., 66, 39.

Goodhill, V. (1950). Ann. Otol., St. Louis, 59, 1123.

Govan, A. D. T. and Scott, J. M. (1953). Lancet, 1, 611.

Johnsen, S. and Freiesleben, E. (1952). Acta Oto-laryng., Stockh., 42, 35 .

Lewy, F. H. and Kobrak, H. (1936). Arch. Neurol. Psychiat., Chicago, 35, 839.

Mollison, P. L., Mourant, A. E. and Race, R. R. (1952). Med res. Coun., Memo. No. 27

Orth, J. (1875). Virchow's Arch., path. Anat., 63, 447.

Whetnall, E. (1952). In Scott-Brown, W. G. Diseases of the Ear, Nose and Throat, vol. 2, ch. 16. London. 